\title{
Fairness, Free-Riding and Rainforest Protection ${ }^{1}$
}

\author{
Forthcoming in Political Theory
}

I.

The Yasuni National Park in the East of Ecuador contains close to 900 million barrels-worth of crude oil, or roughly a fifth of Ecuadorean reserves. As a developing economy Ecuador is highly dependent on petroleum-related exports, and as such has an interest - and, as it happens, an interest protected under the international law of "permanent sovereignty over natural resources' - in extracting that oil. At the same time, however, the Yasuni National Park is an important tropical rainforest: it is a haven for biodiversity; it contains several 'uncontacted' indigenous tribes; and it functions as a significant carbon sink.

Consider the last fact in more detail. The world's forests are tremendously important repositories for greenhouse gases; they contain roughly 650 billion tonnes of carbon, the equivalent of 2,300 billion tonnes of carbon dioxide. This is more than four times the amount of $\mathrm{CO}_{2}$ emitted by humanity since the beginning of the industrial revolution. Among the world's forests, rainforests are especially effective at sequestering $\mathrm{CO}_{2}$, whereas their destruction not only erodes that sequestering capacity but releases huge quantities of $\mathrm{CO}_{2}$ back into the atmosphere, thereby potentially accelerating dangerous climate change. Indeed while we await the fruition of grandiose projects of geo-engineering, the protection, enhancement or extension of rainforests is often thought to be the one serious option available for slowing rises in greenhouse gas levels in the world's atmosphere. ${ }^{1}$

\footnotetext{
${ }^{1}$ For written comments or instructive questions, thanks to Oliviero Angeli, Megan Blomfield, Simon Caney, Matthew Clayton, Clare Heyward, Andrew Mason, David Miller, Ed Page, Massimo Renzo, Cedric Ryngaert, Fabian Schuppert, Zofia Stemplowska, Adam Swift, Steve Vanderheiden and Kit Wellman.
} 
All of which produces a dilemma for the people of Ecuador. They can either protect the rainforest in Yasuni - thereby foregoing opportunities for economic development - or extract the oil, but reduce our collective capacity to avoid dangerous climate change. But we might ask, of course, why it is the people of Ecuador who should face this dilemma, rather than all of us. Protecting rainforests has costs: these include direct costs, as when resources are spent keeping out illegal loggers, or when forests are tended and replanted. They also include opportunity costs, as when an agent, in protecting forests, foregoes the benefits from economic development which might otherwise have been secured. Who those costs ought to be borne by is an important question for a theory of global justice. Notably, the rainforests of our world are concentrated in several clusters, with the lion's share falling within the territories of developing states in South America and Africa. Should the inhabitants of those states bear the costs of protection alone?

The view of Ecuador's government is that the answer to the last question must be a resounding negative. In 2010 it established the Yasuni Ishpingo-Tambococha-Tiputini Initiative, comprising a fund administered by the United Nations Development Program. ${ }^{2}$ Foreign governments, charities and individuals were invited to contribute towards a fundraising target of US\$3.6 billion by the year 2023. If that target was met, Ecuador declared that the oil field would not be developed. If not, it would be. The choice for the rest of the world was simple: if you believe that we ought to protect the Yasuni forest, share with us the costs of doing so.

The Initiative was controversial, and in August 2013 it was declared a failure and disbanded, having achieved actual deposits (as opposed to promises) of a mere $\$ 13$ million. ${ }^{3}$ One set of concerns revolved around issues of partial compliance: for instance if (as many people feared) the Initiative failed to reach its target, what would happen to any deposits made? But there were also deeper normative questions: Did the Initiative represent, as was 
suggested at the time of its inception, an objectionable form of ecological hostage-taking ('give us the money or the forest dies')? Should we consider any donations made supererogatory ('good but optional') moral acts, or are outsiders bound by justice to share in the costs of rainforest protection?

Two broad arguments could be appealed to in order to support the conclusion that outsiders do have duties of justice to share in those costs. One would be an egalitarian argument which suggested that, if it is unjust for some communities to face inferior opportunities merely because of the relatively meagre shares of natural resources existing within their territories, ${ }^{4}$ then it must also be unjust for some countries to bear greater burdens simply because the resources contained within their territories happen to be ones which justice requires the protection (and non-exploitation) of. If justice requires the pooling of benefits, then it likely also requires the pooling of at least some burdens.

Whilst many will be sympathetic to that argument - including the present author - it is not the argument Ecuador is presenting in defence of its claim to protection payments. The argument from Ecuador is of a different character, suggesting that outsiders should pay not to offset some cosmic arbitrariness, but rather because they are in receipt of important benefits the costs of securing which are currently being borne by Ecuador. ${ }^{5}$ The argument appears to turn on a version of the principle of fairness, and this is the argument I will explore in this paper. $^{6}$

Of course it could be that Ecuadoreans have merely overlooked the egalitarian argument, and that it would add greater force and cogency to their demands if they engaged with it. That diagnosis seems unlikely. Rather than overlooking the egalitarian argument, Ecuador appears to be deeply committed to a principle of permanent sovereignty over natural resources which is usually taken to stand at odds with it. The crux of its complaint is that if 'its' forests are to be protected, it will have to forego development opportunities which would 
otherwise be its right. Rather than bemoaning that fact this paper capitalises on it, because it opens up a very important possibility. If the argument from the principle of fairness can be made successfully, it may convince political philosophers who endorse self-determination over resources, the conventional prerogatives of nation-states, and who reject global egalitarianism as a controversial or overly demanding or ambitious doctrine, and ordinary citizens and politicians who are often just as wedded to the principle of permanent sovereignty. Given that rainforest protection is an urgent requirement if dangerous climate change is to be averted, and given that programmes aiming to divert funding to rainforest protection are chronically underfunded, ${ }^{7}$ agreement from those quarters would be invaluable.

II.

Some necessary preliminaries. This paper draws upon the 'principle of fairness' to support the conclusion that outsiders are bound by justice to share these costs, and that if they refuse to do so they can be found guilty of free-riding. The principle of fairness is familiar from discussions of public good provision within states, but the argument necessitates its extension across two dimensions. First, it must be shown that the argument can intelligibly be applied across borders. Second, whilst typically applied to cases of public good production, the paper applies the argument to public good protection. What is morally significant about public good production - and what potentially gets the debate about free-riding going - is that agents sink costs into securing benefits which then accrue to other agents (who are potentially able to avoid sharing those costs). But protection displays the same features: when a rainforest - or any other resource which provides important 'ecosystem services' - is protected against some threat which would diminish or destroy its capacity to provide those services, agents are once 
more sinking costs into securing greater benefits than would counterfactually exist, outsiders cannot be excluded from those benefits, and the same possibility of sharing or refusing to share in those costs emerges. Beyond these two extensions, we must also face a series of formidable challenges to the principle which have attempted to circumscribe the class of cases to which it can intelligibly apply, with attempted scope-restrictions chiefly focusing on the intentions of both consumers and producers of public goods. The present paper shows that the rainforest case can survive these challenges, and in demonstrating that it also advances our understanding of the principle and its scope. It provides, the paper suggests, the most compelling formulation of the arguments of forest states. But if successful the argument will also have implications beyond those cases.

A few comments about public goods are also in order. In the case of many natural resources - such as oil, diamonds and gold - the benefits arising from those goods are typically highly excludable, a fact which marks them out as examples of private goods. Rainforests, however, are Janus-faced. They can function as private goods, as when trees are felled and used to build houses and furniture. But if left intact they deliver benefits from which outsiders cannot be excluded. This marks them out as examples of public goods, ${ }^{8}$ and explains the relevance of the principle of fairness to the question of how to share the costs of their provision or protection. Note, however, that there is some diversity within the category of public goods. In the case of a 'pure' public good consumption is not only non-excludable but non-subtractive, so that consumption by one agent does not leave less for subsequent consumers. 'Collective' goods, on the other hand, share with pure public goods the feature of non-excludability, but not the condition of non-subtractiveness. ${ }^{9}$ In the case of collective goods when an additional person begins to consume this immediately leaves less for others. Some of the benefits arising from rainforests are best viewed as pure public goods (as when trees produce the benefits of flood-protection or the sustaining of biodiversity), but others are 
best viewed as collective goods (as when trees absorb carbon dioxide: we consume quite unequal quantities of the sequestering capacity of the carbon sinks of the world, and each time a person is born the demands on that shared resource are intensified). Though it has been neglected within discussions of the principle of fairness, it is shown below that the difference between pure public goods and collective goods has significant normative import, and that the argument from the principle of fairness goes through much more easily in the latter case.

Section III of this paper introduces the principle of fairness, and sketches a stylised case in which one country protects the carbon-sequestering capacities of rainforests, thereby securing a collective good which is also enjoyed by others. Section IV then considers some forceful arguments to the effect that we should constrain the scope of the principle to cases in which consumption meets certain conditions. It shows how the rainforest case survives those objections. Section V considers a further set of attempts to constrain the scope of the principle to goods which are produced in certain ways. It shows that the rainforest case can survive those attempts, and, moreover, it defeats the claim that beneficent intentions are a necessary condition for the principle to apply. Section VI argues that, once the argument for sharing the costs of protection has been admitted, it plausibly adumbrates both direct and opportunity costs, including, therefore, the value of foregone opportunities for economic development.

Section VII concludes that pooling the costs of protection is required by justice, and that the principle of fairness provides a compelling account of why that is the case. If the argument is successful then it appears plausible that it could apply to the protection of other natural resources which deliver important ecosystem services, where costs are localised but benefits are enjoyed more widely. The paper, though, concentrates on the - hugely significant - case of rainforests. More broadly, it takes no official position on the question whether the costs of rainforest protection should be pooled in isolation from other benefits and burdens 
relevant to natural resource justice, climate justice more broadly, or global justice still more broadly, or whether they should be integrated with them. It may be plausible, for instance, that they should be integrated as one datum amongst many others relevant to calculating just distributive shares. ${ }^{10}$ Alternatively, it might be plausible given the urgency of rainforest protection to secure agreement on rainforest protection first, at least at the level of policy. The paper merely aims to demonstrate what is a significant enough conclusion, to the effect that powerful reasons exist for sharing the costs of rainforest protection globally, and that if outsiders refuse to do so we are guilty of free-riding; and in so doing it shows that even those sceptical about the egalitarian argument from the inherent arbitrariness of natural resource distribution can, in this vital case at least, be brought to converge on the same conclusion.

\section{III.}

In discussions of the provision of public goods, the dangers of 'free-riding' have received considerable attention. A free-rider is depicted, typically, as someone who consumes ${ }^{11}$ nonexcludable goods but avoids paying anything towards their provision. When I avoid sharing in the costs of provision I exploit the difficulties of enforcing payment and thereby oblige others, inappropriately, to subsidise my own ends. ${ }^{12}$ The principle of fairness provides an account of just when those who benefit from the provision of public goods ought to share in the costs of their provision and just when, correspondingly, refusing to assume a fair share of those burdens is morally objectionable. ${ }^{13}$

The kind of discrimination which the principle seeks to underpin is important, because it cannot be the case that costs should be pooled whenever someone produces nonexcludable goods. By common consent the charge of free-riding cannot apply to cases where 
the provision of public goods is woefully suboptimal, in which it fails to serve genuinely shared interests, or in which costs are not fairly shared. Discussion has centred on cases where the collective provision of a non-excludable good is the optimal solution - where collective provision, that is, is obviously superior to a scheme in which individuals seek to advance their own ends individually and hence is worth its cost - and where the share of costs which beneficiaries are asked to pay is a fair one. ${ }^{14}$

The last point bears closer scrutiny, because the principle does not by itself appear to settle the question of what constitutes a fair share. It might produce a presumption, we could say, towards tailoring the share of costs to the scale of benefits each agent enjoys. But potentially, a variety of views on what constitute distributively-fair shares might intervene when it came to determining the share of costs any one agent should ultimately bear. To keep that possibility open the paper assumes throughout that the conclusions delivered by the principle are pro tanto ones. For cases meeting certain conditions, the principle identifies a pool of agents who are morally liable to bear costs. But perhaps, in any particular one of these cases, we know that agent $\mathrm{N}$ has a much higher disposable income than agent $\mathrm{O}$. Where this is so, some accounts of fair shares will find it intelligible to require $\mathrm{N}$ to contribute more than O. Perhaps, in an extreme case, requiring agent $\mathrm{P}$ to bear any costs at all would tip her into severe poverty, and hence it may make moral sense to exempt her. If so a pro tanto duty to share in costs is being modified - or, in extreme cases, defeated - by the appearance of something like an ability-to-pay principle. The kinds of exemptions that this generates are commonplace within welfare states and as such are, properly understood, part and parcel of the business of the principle of fairness in practice. The principle identifies a pool of potential contributors, but may not fully determine the allocation of costs between those agents.

The principle of fairness, suitably constrained and qualified, can give force to our intuitions about when and how the costs of securing public goods should be shared. It has 
often been thought, more expansively, that such an account provides the beginnings of an answer to the question why citizens ought to obey the state. ${ }^{15}$ That issue will be bracketed here: rather than focusing on such 'political' obligations, this paper focuses on duties to bear a share of the costs of rainforest protection. Likewise, it focuses not on duties to cooperate to secure public goods, but on duties to share the costs of public goods which are secured. Significantly, it is plausible to hold that moral duties to share costs can cross borders, regardless of whether we believe that political obligations intelligibly can. ${ }^{16}$ Consider the following example:

Poisoned Lake. A lake spanning two countries sustains fishing industries upon which both depend. Tomorrow the government of country A discovers an underwater geyser, just on its side of the national boundary, which has started to belch out methane. Uncontrolled, the methane will soon destroy all of the fish which the lake currently provides (equally) to both countries. Placing a concrete cap on the geyser will be expensive, and the government of $\mathrm{A}$ asks the government of $\mathrm{B}$ to share in the costs.

Here country A, in capping the geyser, is responsible for the continued existence of a good upon which both countries depend. Whilst country B can refuse to share the costs of protection - and, indeed, it might be 'rational' for them to do so, in the knowledge that if so country A will go ahead and bear the costs itself, given the lack of any coercive institution capable of enforcing cost-pooling - it is hardly just for them to do so. To make the injustice still more apparent, we can stipulate that the reason it is necessary for country A to cap the geyser is that the fishing activities of both countries have disturbed it, and that the amount of concrete required to cap the geyser - hence the cost of the cap - is directly related to the 
incidence of fishing. In that case, for country B to refuse to contribute is still less defensible: the cost borne by $\mathrm{A}$ is imposed by an activity which both countries benefit from, and the scale of the cost increases in a linear fashion with the degree of benefits which country $\mathrm{B}$ (along with country A) extracts. Notably, many cases considered by scholars of the principle of fairness involve consumption of pure public goods, where the arrival of one more consumer does not load more costs onto providers. But the Poisoned Lake situation is different - and can be considered a case of free-riding par excellence - insofar as the costs imposed on the agent protecting a public good rise in direct proportion to the benefits enjoyed by others (who refuse to share those costs). As I argue in section V, it is far from obvious why the fact that the benefits in question accrue across national borders rules out such a conclusion.

But if examples of this variety have any persuasive power, they should convince us to devote serious attention to the costs associated with the protection of important ecosystem resources such as carbon sequestration. Unfortunately they have received limited attention from theorists of distributive justice to date, perhaps because of a mistaken belief that significant public goods are seldom supplied transnationally. ${ }^{17}$ For instance, Andrea Sangiovanni's restriction of principles of equality to the domestic level is premised precisely upon the idea that important public goods are only provided to each other by co-citizens, triggering egalitarian principles sharing benefits and burdens between them, but not across borders. ${ }^{18}$ But this is false: even if we adhere to Sangiovanni's inordinately brief list of two key public goods (physical security and a property system) it is evident that they are frequently supported at least in part by agencies outside of individual states; if we are willing to think beyond physical security and a property system, we quickly arrive at other public goods which are similarly vital but whose delivery is not neatly demarcated according to state boundaries. Environmental public goods are a case in point. The benefits provided by 
important ecosystem resources - such as carbon sequestration - may be vital, but are no respecters of national boundaries. Moreover they appear to easily meet the conditions for discussion under a principle of fairness outlined above. The goods provided are nonexcludable, in the sense that no-one can be prevented from enjoying them. And their provision is also typically very cost-effective when compared to the alternatives: although rival methods of carbon sequestration have been mooted, for instance, they have not established themselves as anything like as cost-effective as the normal sequestration capacities of rainforests. The moot point, in the case of rainforests, is not whether the benefits provided are non-excludable or whether they are worth their cost. The point of contention is whether the costs should be borne by locals, or else shared more widely.

To keep the inquiry manageable, in what follows we will concentrate upon one relatively straightforward type of case, in which a rainforest is contained within a particular community, but provides non-excludable benefits to all of humankind. We will also concentrate on one benefit only: the collective good of carbon-sequestration. Nothing much turns on that restriction other than the manageability of the discussion. We need not assume that forests should only be protected because of their sequestration function. They might be thought to be intrinsically valuable, or to support valuable biodiversity, or to harbour indigenous tribes whose ways of life have distinctive value; if so then the project of protection becomes still more important, and good policy would have to find some way of advancing all three goals. But still, paying due attention to the good of carbon-sequestration is enough to motivate the case for protection, and the moral case for sharing its costs. I return to the question of advancing the other goals in section VII. The fact that our emissions are sequestered somewhere, and that existing stocks of carbon are not unlocked, is essential in order to avoid dangerous climate change. Our question will be about where any costs 
involved in securing the good of sequestration and storing should fall. Call to mind, then, a community called Arborea:

Arborea wishes to advance economically, but the most assured way of doing so will involve cutting down substantial parts of its native forests. The rainforests within its territory, though, produce carbon sequestration functions upon which all depend. In the face of the predictable protests it maintains that it is unfair that it alone should bear the costs of protecting the forest, and argues that if it is to refrain from deforestation then those costs should be shared among all beneficiaries - that is, between all of us.

Key features of this case are as follows: the benefits in question are non-excludable: Arboreans cannot decide whose emissions the trees will sequester, or prevent outsiders from using up their absorptive capacity. Secondly, I stipulate that they are necessary: if disastrous climate change is to be averted, it is essential that emissions are sequestered; ${ }^{19}$ but although carbon capture projects have been mooted, no large-scale alternatives to (Arborean) rainforest sequestration exist. If that changes, then the moral situation changes too (see below). But in the immediate future it appears highly unlikely to. This means, amongst other things, that it is intelligible to say that Arboreans are under a duty of justice to protect their rainforest, a position which is compatible with the view that outsiders are under a duty to share in the costs of their performance of that duty (see section VI). Finally, they are subtractive: sequestering capacity is finite, and hence by definition each unit of sequestering capacity used up by anyone leaves less for others. Notice, in particular, that the amount of its forest that Arborea must preserve to avoid dangerous climate change is not a function of its own level of emissions but of the total level of emissions worldwide. Outsiders determine, along 
with Arboreans, how much rainforest needs to be protected and hence how costly that protection will be. In those circumstances, then if outsiders refuse to share in the costs of protection a charge of free-riding is appropriate.

But before endorsing that conclusion we need to face a series of bracing criticisms of the principle of fairness, which suggest that the range of cases to which it can be applied it narrower than we might suppose. Those challenges must be either rejected, tamed or avoided for the conclusion in the Arborean case to be secure.

\section{IV.}

Our first objection holds that it is only appropriate to invoke the principle of fairness in cases where shared benefits are consumed in certain specified ways. The core thought is that it creates a perverse moral hazard if we are authorised to impose cost-sharing duties upon people by thrusting upon them services they have no desire for - by, in Nozick's famous example, throwing books in their windows and then demanding recompense. On Nozick's view this is impermissible: 'One cannot, whatever one's purposes, just act so as to give people benefits and then demand (or seize) payment. ${ }^{20}$ John Simmons has usefully focused this general line of attack by suggesting two necessary conditions for the principle of fairness to apply: benefits must be knowingly and willingly accepted. ${ }^{21}$

One well-known response to Simmons's objection invokes a set of 'presumptively beneficial goods' which are essential for any minimally tolerable human life. The thought here is that even if the principle of fairness ought not to apply to 'dispensable' or luxurious public goods, requiring people to pay a share of the costs of producing (or protecting) goods which they uncontroversially need is less problematic. ${ }^{22}$ A similar move is in order in the 
Arborean case: without the carbon-sequestering functions of rainforests - if all of the world's rainforests burned tomorrow, for instance, ceasing to sequester carbon and unlocking it in vast quantities - everyone's most basic projects would very quickly become seriously disrupted and many lives would be endangered. But if carbon emissions must be sequestered somewhere, and if people have not made private arrangements to offset their emissions, they appear liable to share in the costs of the one scheme - the Arborean one - which can secure this good.

But does this move meet Simmons's challenge? Take the knowledge condition first. For a benefit to be knowingly accepted it must, for Simmons, be the case that we know that it is produced by someone and that there are costs attached to producing (or here protecting) those benefits. This, on Simmons's view, holds even if the good in question is genuinely necessary to each agent. ${ }^{23}$ We could observe, here, that the knowledge condition does not appear likely to present major problems for Arborea-type cases. The role of the rainforests as 'the lungs of the world' is well-known even to schoolchildren, after all. In all but marginal cases we know roughly where rainforests are located and that there are costs attached to protecting them. Citizens in the developed world - and their leaders - regularly bemoan the deforestation of the Amazon, for instance, because its carbon-sequestration function is wellunderstood. And whilst there has been little readiness in practice to share in the costs of protection, it is not usually denied that costs exist. The point at issue is who should bear them. We might suppose, then, that the moral situation changes once we make clear to outsiders that they are dependent on public goods, and that their production or protection is not costfree. But for Simmons, importantly, pointing this out is insufficient, because it is the belief that results (or fails to result) which matters morally. We might then be forced to try to establish that those who refuse to believe in that dependence or in those costs (which facts we 
have stipulated are factually true) are culpable in their failure to develop the appropriate beliefs.

My response is a more fundamental one. I deny that acceptance of the costliness of production or protection is necessary to generate duties to share in those costs (and as a logical consequence, I submit that innocent free-riding is an intelligible category and not an oxymoron). The apparent plausibility of the knowledge condition, it seems to me, rests upon ambiguity about the role that the principle of fairness is supposed to play in moral argument. Distinguish two questions: on the one hand, we have the question of whether agents have a duty to share in the costs of producing or protecting (here: necessary collective) goods. On the other hand, we have the (subsidiary) question of whether, when agents fail to act on a duty to share in those costs, their (in)action is morally blameworthy (in the sense that it plausibly justifies public disapprobation, for instance). The challenge posed by Simmons appears highly relevant to our second question, about just when free-riding is an appropriate target of opprobrium, by supplying an account which ties opprobrium to specific features of free-riders' intentions. And Simmons's attempted narrowing of the scope of the principle hinges on the fact that it is sometimes - perhaps often - difficult to reliably attribute those intention-specific features to concrete cases. As Simmons ${ }^{24}$ points out, ignorance may sometimes look 'culpable' or, as another theorist has recently put it, 'motivationally-biased' and self-serving, ${ }^{25}$ but in other cases ignorance appears innocent. In the latter cases, he claims, the charge of free-riding is a fish out of water.

My argument, though, is officially uninterested in the question whether free-riding is deserving of this kind of opprobrium. It is perfectly possible that cases of free-riding exist where agents innocently fail to realise that they are dependent on necessary collective goods and that their dependence obliges others to bear greater costs. When that is the case, it plausibly influences the stance we should take towards free-riders, so that our correct 
response is not to condemn them for parasitism, say, but merely to draw their attention to the fact that their actions are inadvertently loading costs on to others, and require them to desist. My argument is that innocence about costs by no means rules out those agents having duties to share those costs in the first place, and that there is at least one class of goods - broadly, collective goods the protection or production of which is mandated by justice - in which the knowledge-related scope restriction is implausible. In cases of pure public goods - on which libertarian objections to the principle of fairness tend to hinge - consumption is nonsubtractive and innocent ignorance is, as a consequence, cost-free. My argument can stay neutral on whether this attenuates or defeats any duties to share in the costs. But in the Arborean case, in which consumption is subtractive, greater costs are imposed on those who pay for protection or production by the very fact of others' consumption. And given that we have already stipulated in the Arborean case that protection is necessary, we are pushed towards the conclusion that all of those who benefit are liable to bear a fair share of costs whether or not they accept that those costs exist. When we consider the issue from the perspective of those who are currently bearing the costs of protection - who are being asked, under the knowledge condition, to bear greater costs whenever someone sincerely denies that a necessary, costly benefit is indeed necessary or costly - it is hard to see why we would deny that, regardless of its blameworthiness or innocence, loading additional costs onto others in this way is a pro tanto wrong.

The willingness condition suffers a similar fate in the case of collective goods whose protection or production is mandated by justice. A willingness condition asserts that it is inappropriate to invoke the principle of fairness so as to demand that people contribute to the costs of schemes whose benefits they have no desire to partake in. In Arborea-type cases, a quick but rather ad hoc way to rebuff this suggestion would suggest that in the real world the carbon-sequestering services of the rainforests are solicited: national and international leaders 
regularly visit countries like Brazil or Ecuador and entreat their leaders to halt deforestation. They even, from time to time, offer economic inducements such as 'debt-for-nature deals'; we appear to have, rather than an unsolicited benefit, a benefit the price of which the wealthy are still haggling over. But that would only be a fully satisfying response if we knew that such entreaties represented the wishes of all of us, and this is unlikely to be true. What, then, of people who would genuinely prefer not to benefit from the carbon-sequestration functions of the Amazon, whatever their leaders sometimes say? What can we say to those people?

Again, a more fundamental response is possible. It is a feature of our case that rainforest protection is necessary. We can grant - and should grant - that those who offset their emissions have already discharged their duty to share in costs and bear no further duties (see note 19). We can also grant - and should grant - that if alternative forms of sequestration become available through some successful geo-engineering project or other, the moral situation would change. If those alternatives were cheaper than rainforest protection, not least, then rainforest protection ceases to be worth its costs - ceases to be necessary, in fact and that reason for rainforest protection recedes. ${ }^{26}$ That concession, as Simmons is aware, may be a thorny one for those who would build an account of political obligation on the back of the principle of fairness (because it appears to challenge duties to obey particular states when other states can provide the same services more cheaply), but that is not our concern here. In this sense, therefore, we can happily agree that benefits must be voluntarily accepted: where (and only where) alternative providers are available, those who wish to defect from particular schemes providing necessary collective goods cannot be accused of free-riding (on the proviso that what they do consume is not cadged from some other scheme whose costs they are not sharing either). But what is not tenable - and ought to be considered free-riding is consuming sequestering capacity whilst doing nothing to share in its costs anywhere. What is objectionable, in the absence of such schemes and in the absence of offsetting one's 
emissions, is to refuse to contribute to the costs of maintaining the greenhouse gas sinks we do currently have, but to continue to consume their capacity and thereby reduce the opportunities of others. And in the case of collective goods whose protection or production is mandated by justice, that conclusion goes through whether we would wish to depend on these goods or not. Willingness, and not only knowingness, fails to make its case as a necessary condition for the bearing of duties to share in the costs of (at least some, important cases of) public good provision.

\section{V.}

We should also consider a second set of objections which would restrict the principle of fairness to goods which have been produced in certain ways. Perhaps it matters which people produce public goods, for whom. It might be argued that the principle ought not to apply to costs incurred by members of one cooperative scheme in producing or protecting benefits which are in fact enjoyed by others. On one view, it might be the lack of a single cooperative scheme spanning all beneficiaries which makes a normative difference. ${ }^{27}$ It is hard to see, though, why we should place such a restriction on the operation of the principle of fairness. Look again at the Poisoned Lake case. In that case a good has to be protected, or else the vital interests of members of more than one community will be seriously affected. And someone needs to pay for that provision or protection. Even if there is currently no single cooperative scheme to fairly distribute the benefits and burdens, this does not make it fair to land one community with all of the costs of provision or protection. To the contrary, such cases might even provide a good context for the duty to set up wider institutional schemes to regulate background injustice. 
On another version of the objection, perhaps it is the intentions of producers or protectors which matter. That, in any case, is the suggestion of Paula Casal and Andrew Williams, and of Simmons. It is entirely possible that, in the absence of a cost-pooling scheme, Arboreans would choose to protect their rainforests in any case, in defence of Arborean citizens' interests (just as country A, if country B offered no assistance, would presumably cap the geyser in Poisoned Lake at its own expense). But if benefiting others is a merely accidental result of actions which agents are going to undertake in any case, does the same pressure to share the costs arise? Might our knowledge of such intentions not caution against applying the principle of fairness? Even if the intentions of consumers do not matter in quite the way suggested by some critics of the principle, don't the intentions of producers matter? We might distinguish a number of versions of this challenge. A relatively weak version of the challenge would hold that the principle only applies to cases where costs are considered costs by producers or protectors, and where they actually intend to produce or protect benefits (whoever those benefits are for). ${ }^{28} \mathrm{~A}$ stronger version of the challenge would hold that for the principle to apply, it must be the case that producers or protectors intend to act beneficently with regards to agents other than themselves: that part of their explicit intention, we might say, is to act with at least one eye towards the 'common good,' or at least that enabling the consumption of others is an irreducible part of the motivation for production or protection. ${ }^{29}$

The weak version of the challenge does not represent an obstacle for my argument, since the Arborea and Poisoned Lake cases meet its conditions (as is usually true of cases of environmental protection ${ }^{30}$ ). In both cases protecting countries act with the intention of securing the continued existence of benefits, and the costs of doing so are considered costs by those who protect. The same cannot, however, be said in response to the stronger version. Hence it represents a serious obstacle if the conditions it specifies are justified. In Poisoned 
Lake, recall, we did not attribute to country A any irreducible desire to advance the interests of country B: if country B did not exist, country A would still act in the same way (by capping the noxious geyser), and its motivations are explicable with reference to its own interests alone.

But consider that while in Poisoned Lake the motivations of country A are explicable in a purely self-regarding fashion, its costs of action are not. In the case of collective goods consumption is subtractive, and hence the fact that country B cannot be excluded from consuming the good in question means that the costs borne by country A are higher. The same point applies to Arboreans, the costs borne by whom rise in proportion to total world emissions, rather than in proportion to their own emissions alone. ${ }^{31}$ In those circumstances outsiders' refusal to pay a share of those costs appears egregious even if neither Arboreans nor inhabitants of country A have any regard for the interests of outsiders. In reaching the conclusion that the costs of protecting necessary collective goods should be pooled, we can therefore deny that intentions to advance the common good are necessary. What is salient, instead, is that it is morally required that somebody bears costs, and that the non-excludable nature of the benefits concerned means that outsiders are able to unilaterally load those costs onto protectors who cannot avoid incurring them.

The strong version of the challenge fails, then, in cases of necessary collective goods. Indeed this particular attempt at scope-restriction also faces embarrassment in cases of necessary pure public goods, in which it will not reliably deliver plausible conclusions either. Establishing that fact is not necessary for my argument, but it is worth demonstrating because it reveals the deep implausibility of the stronger version of the challenge. Consider the following example, with three different outcomes: 
Manna Destruction. Human life depends upon the existence of 10 units of a mannalike good (regardless of how many people exist). Manna is produced by plants, and each person, in a ten-person world, owns land containing enough plants to produce 10 units each. One night people observe a meteor storm which will, the next day, destroy all manna-plants unless costly shelters are constructed.

Outcome 1: the ten inhabitants agree to each protect sufficient plants to produce 1 unit of manna.

Outcome 2: the ten inhabitants discuss each protecting sufficient plants to produce 1 unit of manna, but one of them volunteers to protect all of his own manna-plants instead.

Outcome 3: the inhabitants discuss each protecting sufficient plants to produce 1 unit of manna, but then notice that one inhabitant is still asleep. The other nine go back to bed secure in the knowledge that when he wakes up, he will have to protect all of his plants. When he wakes up he is furious, wishes in no way to benefit those who have tricked him, but grudgingly protects all of his manna-plants.

Assume that Outcome 1 is just. What do we want to say about the other two outcomes? If the stronger version of the challenge from beneficent intentions is correct, then our critic must agree that there can be a claim to cost-pooling under Outcome 2, but not under Outcome 3. But those are the wrong conclusions.

In Outcome 2 it is plausible to suggest that intentions do make a normative difference, but the way in which they matter is not tracked by the stronger version of the challenge. One thing which becomes apparent, considering this case, is that the stronger version of the challenge suffers from a lack of clarity about what counts as intending to benefit others. We need to know, to be specific, whether acting in order to benefit others denotes an intention 
simply to secure benefits for others, or whether it also necessarily includes an intention to bear the costs of doing so. I will return to the first clause later, but it is relatively easy to see why the second clause cannot be a plausible condition for obligations to share costs to arise. To see why, consider what it would commit us to. If (and only if) our lone protecting agent under Outcome 2 intends not only to benefit the other nine inhabitants but also to bear the costs, then we are committed to saying that costs should be pooled - but in this case the argument for cost-pooling appears rather redundant. As defenders of the principle have themselves suggested, intentions may qualify the scope of the principle in cases of giftgiving. ${ }^{32}$ Embracing our second clause, though, would implausibly restrict the principle to cases of gift-giving. If on the other hand our lone agent intended to benefit the other nine inhabitants but not to bear all of the costs - if his intention, that is, was to act decisively to ensure that a necessary act of protection did in fact occur, and to ask the nine to pay their fair share of costs later - then we are committed to saying that his intention to later ask for costs to be shared actually cancels any duty the nine might have to share in the costs. But that is surely counter-intuitive (and, moreover, consider the deterrent effect it would place on those who seek to act decisively to tackle urgent threats where collective action is not guaranteed, but where benefits are - as we have stipulated - both necessary and worth their costs). An intention to bear the full costs when we protect goods cannot be a necessary condition for the principle of fairness to apply to those costs.

In Outcome 3 the stronger version of the challenge fares no better. Under Outcome 3 the behaviour of the nine agents is, I submit, a plain exercise in free-riding insofar as costs which are necessary for the good of all are forced onto the shoulders of a single agent, who cannot avoid bearing them. That is the case notwithstanding the fact that our sole producer bears no greater costs than he would bear if he were the only agent living in the world. That counterfactual (much-loved by libertarians), which indicates that the consumption of others is 
in that sense cost-free, leads us astray. A more instructive counterfactual would contrast Outcome 3 with Outcome 1, and ask whether we have any reason to regard a transition from the latter to the former as non-justice-infringing. Furthermore, in arriving at the conclusion that forcing costs onto one agent in Outcome 3 involves injustice, the fact that our lone protecting agent does not intend to benefit the other nine inhabitants appears irrelevant. It does not tell us, in this case at least, that he is not being treated unfairly when others require him to bear all of the costs of protection. We do not need to know that our lone agent intended to bear the costs of protection (for he did not). And neither, moreover, do we need to know that an irreducible element of the explanation of his behaviour was that he intended to benefit others (he did not). Neither condition, then, is necessary for the principle of fairness to apply. This brief example cannot show, naturally, that intentions never matter. But it does show that beneficent intentions are not a necessary condition for the principle of fairness to apply. The attempted producer-side scope-restriction fails not only to rule out cost-sharing conclusions in Arborea-type cases, but in at least some cases where consumption is nonsubtractive too.

\section{VI.}

The argument thus far has endorsed the pro tanto claim that the costs of protecting the carbon-sequestering capacity of rainforests ought to be shared between beneficiaries. But perhaps agreement on that might depend, in part, on how expansively we understand the set of morally relevant costs. The argument, we might suppose, will be easier to make in the case of direct costs. Suppose that Arboreans have to spend \$200 million in protecting their forests from threats from fire, flood, gnawing insects, and so on. If costs have been incurred, if the 
threats were genuine, and if the share of costs we will ask outsiders to pay are at least matched by the value of the benefits they are thereby able to enjoy in continuing to emit carbon dioxide without dangerous climate change, the argument for cost-sharing appears relatively straightforward.

But it is possible that the opportunity costs of rainforest protection will be much greater than the direct costs. They represent the potential income foregone when factors of production are used in one way rather than another. If we assume maximal economic rationality, then the opportunity cost will be the value of the next-best alternative use to which factors of production such as natural resources could have been put. In practice resources are not always used to their full economic potential, and where this is so opportunity costs can exceed current revenues. This is likely the case with rainforests: a particular hectare of rainforest, we might imagine, delivers fairly meagre economic benefits to its Arborean inhabitants, but could generate much more if felled for timber and converted to grazing pasture. This, we can further imagine, is precisely why Arboreans want to clear it.

But should opportunity costs be shared? I want to consider an objection to sharing opportunity costs which holds that sharing opportunity costs is inappropriate in cases where the person apparently bearing the cost of not doing $\phi$ has in any case a duty not to do $\phi$. If such an objection holds it might bite in the Arborean case, and give us a compelling reason not to share with Arboreans the opportunity costs of preserving their rainforests. We might believe, to be specific, that Arboreans should not tear up their rainforests, that if they did they would commit a serious injustice, injuring even the most basic rights of many people. If so, then perhaps it is inappropriate to use the potential benefits arising from deforestation as a benchmark for calculating transfers. This returns us, in a sense, to the charge that Ecuador is engaging in ecological hostage-taking or blackmail. We may believe that we should not pay 
hostage-takers, because doing so is paying them not to do things they ought not to do anyway.

We can grant, though, that Arboreans should not tear up their forests but still hold that we should pay them for not doing so. For the view that we ought never to be paid when performing duties of justice - or when refraining from committing injustices - should be rejected. It would be easy - but wrong - to conflate the claim that we have a duty to $\phi$ with the independent claim that we have a duty to bear the costs of performing $\phi$. There will be cases where the two will plausibly run together and others where they do not, and the answer may depend on why they have been allocated the first duty. After obliging someone to carry out community work because she had committed an act of vandalism, it would be odd to then underwrite the costs she incurs in doing so (we might think the same in the case of citizens' community service, assuming that making a sacrifice is part of the point of such activities). But when selecting an agent to bear a duty because a task is necessary but he alone possesses the capacity to perform it, it would be much less odd to underwrite the costs he incurs in performing that duty.

Consider the following example. A given community is plagued by wildfires. Its only way of extinguishing them is by pulling water from a deep well, but this requires considerable strength. It selects its ten strongest members, and charges them with remaining close by the well on a rota system. The decision is justifiable, but it also produces distributive unfairness if we refuse to share the costs of performing that duty. And it does not matter, here, which kind of cost we are talking about. One of the people selected points out that since he lives on the farthest reaches of the community, it will cost him $\$ 10$ to travel to the well. Another points out that in order to fulfil her allocated slot she will be too busy to collect $\$ 10$ which would otherwise be due to her. In both cases the argument for defraying those costs 
appears sound - assuming, again, that benefits are worth their costs - and it does not appear to make any difference that the first is a direct cost and the second is an opportunity cost.

We can, then, coherently hold that agents are obliged to do $\phi$ at the same time as recognising that doing $\phi$ is costly for them and that part or all of that cost ought to be defrayed. The claim that Arboreans ought not to chop down their forests does not establish that it is wrong to share in the opportunity costs of rainforest protection. The argument for sharing the costs of protection can survive this objection, especially where we have selected agents to perform a duty because they have some special capability to perform it. Not, perhaps, if the reason we have selected agent $\mathrm{x}$ is that agent $\mathrm{x}$ is very wealthy. But if we have selected agent $\mathrm{x}$ because she has medical skills, or because he is physically able to operate a well, compensation is defensible. Likewise, even if we believe that Arboreans have a duty to protect their forests - since they are the ones who have forests - justice can demand that the costs of performing the duty are shared, and these include either direct or opportunity costs.

\section{VII.}

This paper began with the real-world example of Ecuador's Yasuni Initiative, which implored the rest of the world to share the costs imposed by rainforest protection in the interests of climate security. It went on to provide an argument why outsiders can be bound by duties of justice to contribute funds to such schemes. Indeed if successful the argument may well apply to the protection of other resources which secure significant ecosystem benefits, or to the results of any geoengineering schemes which might come to fruition. In each case we could develop a normative account linking the receipt of benefits with the sinking of costs into protection, and the argument from the principle of fairness provides one such account. 
Although there may be other routes to the conclusion that costs should be shared, several features of the argument from fairness are worth noting. First, I have suggested that it has the potential to convince even those sceptical of the more ambitious arguments of global egalitarians, and who cleave to the principle that nation-states should be sovereign over the natural resources contained within their territories. Second (and not unrelatedly), it reflects the arguments that political actors in the global South are actually making. Moreover, insofar as it draws upon familiar and far from esoteric claims about the wrongness of free-riding, it has the potential to resonate with the arguments of real-world political actors, and to help build political coalitions. Still, we should be clear-headed about what making such an argument can achieve. I do not claim, of course, that simply unpacking and eludicating the argument is sufficient to guarantee progress. As Ecuador's president has pointed out, 'As long as power relations don't change, there will be a lot of rhetoric [in favour of sharing protection costs] and few actions.' On the other hand, Correia has suggested precisely that rather than waiting for fundamental changes to global power relations to emerge, the best hope is to stir the indignation of 'citizens of the North' by revealing the extent to which their lifestyles constitute a form of free-riding on countries enmeshed in poverty, and asking them to 'Imagine for a moment that the situation was the other way around. ${ }^{33}$ This article is a contribution to that project. It suggests that viewing contributions to forest protection as charitable acts is a serious mis-framing. Payments for protection are required if we are not to play a part in keeping developing countries in poverty, leaving them to continue to protect a public good upon which our own lifestyles are all too heavily dependent, at the cost of their own economic advancement.

If laying out the best normative arguments is one important challenge, designing sound policies is another. The paper has defended the view that rainforests should be protected at least because of their sequestering function, and that costs ought to be shared at 
least for that reason. ${ }^{34}$ Nevertheless, the results thus far of schemes to share the costs of protecting rainforests, such as the United Nations REDD+ scheme ${ }^{35}$ (aimed at Reducing Emissions from Deforestation and Forest Degradation), have been decidedly mixed. And this is not only because they have been, to date, chronically underfunded. According to critics, the goal of protecting carbon-sequestering capacity has too often come at the expense of two other significant justice goals: the protection of biodiversity, and the protection of the lifestyles of indigenous communities currently living in the rainforests. On the first goal, critics have suggested that a focus on measuring and securing carbon-sequestering capacity has sometimes led to either a neglect of the value of biodiversity, or at worst, to damage to biodiversity as native forests are razed and replanted by non-native trees which are more efficient at sequestering carbon. In the worst cases, under current incentive structures havens for biodiversity threaten to become 'green deserts,' far less capable of supporting the rich forms of interdependence associated with pristine rainforests. On the second goal, critics point out that local communities are sometimes marginalised - or even excluded - once forests come to be seen as valuable carbon sinks the absorptive capacity of which is to be maximised. Once a formula is in place which disburses funds on the basis of tonnes of carbon sequester per square kilometre, indigenous practices can be seen as a distraction or even a threat. $^{36}$

Critics of such schemes do not, of course, object to the idea that carbon sinks should be protected or, as far as I can tell, to the claim that it would be iniquitous if forest states had to bear the costs of protection alone. But they do strongly object to the way in which policy has been implemented, and in which the safeguards envisaged under the United Nations framework have gone by the wayside. According to those guidelines, priority is to be placed in REDD+ schemes upon both the 'conservation of natural forests and biological diversity,' and the 'full and effective participation of...indigenous peoples and local communities' in 
conservation schemes, as well as their protection from adverse impact. ${ }^{37}$ Neither goal has been realised consistently to date.

But still, we should not accept a counsel of despair about the prospects for a more balanced conservation programme. Many studies have shown that the goals of biodiversity, indigenous participation and sink protection can go hand-in-hand. There is good evidence, for instance, that forest degradation is reduced when local, as opposed to centralised, ruleenforcement is in place, and when benefits from protection schemes are widely dispersed among local inhabitants rather than being monopolised by elites. ${ }^{38}$ Along with failures in forest conservation there have been successes, in which indigenous groups have been active participants and biodiversity has been protected for current and future generations. There is strong evidence, for instance, that the precise methodology employed to measure carbon sequestration makes a significant difference. In particular, participatory monitoring techniques involving local communities in assessing forest health have proven to be (unsurprisingly) effective in spreading benefits and securing indigenous livelihoods, but (perhaps more surprisingly) cheaper than remote expert monitoring techniques whilst being equally effective. ${ }^{39}$ If so, the prospects for designing policies capable of securing a broad range of justice goals - showing appropriate concern for sequestration, biodiversity and indigenous lifestyles - are much better than is often feared. The poor performance of some protection schemes to date certainly points to the dangers of elite capture and the accompanying skewed distribution of benefits; but they do not establish, fortunately, that conservation policy cannot also deliver for indigenous groups whilst securing biodiversity. 
${ }^{1}$ United Nations Food and Agriculture Organization, State of the World's Forests 2012 Rome: United Nations Publishing.

${ }^{2}$ See: http://yasuni-itt.gob.ec/Inicio.aspx.

${ }^{3}$ As reported widely in the world's newspapers. See for instance http://www.theguardian.com/world/2013/aug/16/ecuador-abandons-yasuni-amazon-drilling.

${ }^{4}$ See e.g. Charles Beitz, Political Theory and International Relations (Princeton: Princeton University Press, 1979).

${ }^{5}$ In the words of the Initiative's founder, President Rafael Correia, this is 'money which the country needs to escape poverty. We are prepared to forego that, in order to continue generating a global environmental public good. But we need to be compensated for it.' 'Interview: Ecuador's Path,' New Left Review 77 (2012): 89-104, at 97.

${ }^{6}$ The paper presents an argument from fairness which is intended to generate convergence on the egalitarians' conclusion that costs should be pooled. But, though I will not explore the issue further here, the argument may have implications for egalitarians' positions too. Perhaps an egalitarian is moved to correct even 'cosmic' inequalities such as those attendant on the haphazard distribution of natural resources. Still, if we know that a particular unequal burden is carried by party $\mathrm{x}$ because party y exploits asymmetries in their relationship to avoid sharing in the costs of protecting or providing a good on which they do in fact rely, then that may plausibly make the inequality in question in one respect worse. And that, other things being equal, may influence the priority egalitarians should attach to remedying it.

${ }^{7}$ In that sense the fate of the Yasuni fund reflects, albeit in more dramatic fashion, the chronic under-resourcing of broader initiatives to fund the protection of rainforests and other key natural resources. The UNDP's flagship programme in this area - the Global Environment Facility - faces serious shortfalls in financing and hence capacity to affect protection. For discussion see Lehmann, Ina, Who Gets What in the International Biodiversity Regime? Global Environment Facility Funding for the Conservation of Biodiversity' (unpublished manuscript).

${ }^{8}$ Vincent Ostrom and Elinor Ostrom, 'Public Goods and Public Choices,' in E. S. Savas (ed) Alternatives for Delivering Public Services (Boulder: Westview, 1977), pp. 7-49.

9 Richard Arneson, 'The Principle of Fairness and the Free-Rider Problem,' Ethics 92.4 (1982): 616-33. 
${ }^{10}$ For a discussion of the merits of isolationism and integrationism about climate justice, and a distinction between isolation at the level of ideal theory and policy, see Simon Caney, 'Just Emissions,' Philosophy and Public Affairs 40.4 (2013): 255-300.

${ }^{11}$ Clarity about this is important when we come to consider the rainforest case. It is those who consume the good of carbon-sequestration who stand liable, under the principle of fairness, to fund that protection. The principle stands at odds, in this respect, with a much broader principle such as the beneficiary pays principle. Under the principle of fairness, it is (only) those who emit carbon who should pay. Under the BPP, it is a possible conclusion that anyone who benefits from the sequestration of carbon, however indirectly, should pay. We might then end up with the conclusion that it is those who are most vulnerable to dangerous climate change who should foot the bill for protection. The principle of fairness endorses no such conclusion. It tells us that those who ride state trams should buy tickets; it does not tell us that people who benefit from the lower pollution and safer streets that arise when people ride trams should also pay.

${ }^{12}$ Garrett Cullity, 'Moral Free Riding,' Philosophy and Public Affairs 24.1 (1995): 3-34, at 3.

${ }^{13}$ Notably the idea of such a principle played an important role in the development of John Rawls's theory of justice, and he in turn was influenced by H.L.A. Hart's work on the subject. H.L.A. Hart, 'Are There Any Natural Rights?' Philosophical Review 64 (1955): 17591; John Rawls, A Theory of Justice (Harvard: Harvard University Press, 1971).

${ }^{14}$ Arneson, The Principle of Fairness.'

${ }^{15}$ Cf. A. John Simmons, Moral Principles and Political Obligations (Princeton: Princeton University Press, 1979).

${ }^{16}$ See also David Mapel, 'Fairness, Political Obligation, and Benefits Across Borders,' Polity 37.4 (2005): 426-42.

${ }^{17}$ See e.g. George Klosko, 'Political Obligation and Natural Duties of Justice,' Philosophy and Public Affairs 23.3 (1994): 251-70, at 260-1.

18 Andrea Sangiovanni, 'Global Justice, Reciprocity and the State,' Philosophy and Public Affairs 35.1 (2007): 3-39.

${ }^{19}$ If there are net emissions, of course. There are individuals who profess to live 'zeroemissions' or 'carbon-neutral' lifestyles, who would not, under the present argument, have a duty to share in the costs of rainforest protection. Note, however, that it is not so much the case that these people are not responsible for any emissions at all (which would in any case be impossible: we release carbon dioxide every time we breathe), but rather that their 
emissions are already offset via private schemes for sequestration. These are in fact, typically, schemes for rainforest protection which mirror, on a smaller and voluntary scale, the kind of scheme advocated here. Hence it would be more accurate to say such people have and have discharged duties to share the costs of sequestration.

${ }^{20}$ Robert Nozick, Anarchy, State and Utopia (Oxford: Blackwell, 1974), at p.95.

${ }^{21}$ Simmons, Moral Principles, at p.129.

${ }^{22}$ George Klosko, The Principle of Fairness and Political Obligation (Lanham: Rowman and Littlefield, 1992), at p.39.

${ }^{23}$ A. John Simmons, Justification and Legitimacy (Cambridge: Cambridge University Press, 2001), at p.34.

${ }^{24}$ Ibid, 32-3.

25 Masssimo Renzo, 'Fairness, Self-Deception and Political Obligation,' Philosophical Studies 169.3 (2013): 467-88.

${ }^{26}$ Note, though, that what emerges in its place is an identical question about the benefits arising from these geo-engineering schemes: given that outsiders (presumably) could not be excluded from enjoying their (presumably) subtractive benefits, do those outsiders have a duty to share the costs of the development and maintenance of those schemes? Why, and to what extent? Answering those important questions opens the door once more to the principle of fairness and to potential charges of free-riding.

${ }^{27}$ The idea that people who benefit from the goods produced by cooperative schemes which they are not part of might thereby derive obligations towards those schemes has elicited considerable suspicion. Simmons finds it 'outrageous'; and considers the view that political obligations can result to be especially hard to defend (Moral Principles, p.121, p. 123).

${ }^{28}$ Paula Casal, 'Environmentalism, Procreation and the Principle of Fairness,' Public Affairs Quarterly 13.4 (1999): 363-76. For useful clarification of and critical engagement with the idea that costs must be felt as costs, see Serena Olsaretti, 'Children as Public Goods?' Philosophy and Public Affairs 41.3 (2013): 226-58.

${ }^{29}$ Simmons claims that there needs to be 'conscious sacrifice for the common good' in order for considerations of fairness to arise (Moral Principles, p. 40). See also Paula Casal and Andrew Williams, 'Rights, Equality and Procreation,' Analyse \& Kritik 17.1 (1995): 93-116.

${ }^{30}$ Casal, 'Environmentalism, Procreation,' at 367-9.

${ }^{31}$ In a recent discussion of the costs of raising children, Serena Olsaretti has made a similar move in response to Casal and Williams, arguing that production-side reservations about the 
principle of fairness falter in cases where consumption of benefits by non-producers actually drives up the costs of production (in this case, the costs of raising children). Olsaretti's argument does not seek to vindicate the principle of fairness, but a cousin principle applying to excludable goods. Olsaretti, 'Children as Public Goods?' at 243.

${ }^{32}$ See e.g. Arneson, 'The Principle of Fairness,' at 618.

${ }^{33}$ Correia, 'Ecuador's Path,' at 97.

${ }^{34}$ Although Ecuador has famously protected the 'Rights of Nature' in its Constitution, it is worth noting that the Yasuni Initiative implores outsiders to defray lost oil income, and makes no claim that outsiders should fund the protection of nature as an end in itself. Ibid.

${ }^{35}$ See http://www.un-redd.org/

${ }^{36}$ For a discussion of those concerns, see Nicholas Anderson, 'REDDy or Not? Effects on Indigenous Peoples in Brazil of a Global Mechanism for Reducing Emissions from Deforestation and Degradation,' Journal of Sustainable Development 2.3 (2009): 18-28.

${ }^{37}$ For a discussion of the safeguards under the United Nations Framework Convention on Climate Change, see:

http://www.unredd.org/Newsletter35/PolicyBriefonREDDSafeguards/tabid/105808/Default.a $\underline{\operatorname{spx}}$

38 Ashwini Chhatre and Arun Agrawal, 'Trade-offs and Synergies between Carbon Storage and Livelihood Benefits from Forest Commons,' Proceedings of the National Academy of Sciences 106.42 (2009): 17667-70.

${ }^{39}$ Finn Danielsen et al., 'At the Heart of REDD+: A Role for Local People in Monitoring Forests?' Conservation Letters 4.2 (2011): 158-67. 